\title{
More Than Meets the Wegener's Eye
}

LARA MEILAK, MD; NIKOLAOS HALIASOS, MD; ALESSANDRO NARDUCCI, MD; MICHAEL POWELL, FRCS, FRCP, Department of Neurosurgery, The National Hospital for Neurology and Neurosurgery, Queen Square, London WC1N 3BG, UK. Address correspondence to Dr. Meilak; E-mail: lara.meilak@doctors.net.uk.J Rheumatol 2013;40:1226-7; doi:10.3899/jrheum.121403

A 61-year-old man with known granulomatosis with polyangiitis (GPA; diagnosed on nasal biopsy) presented with a gritty sensation in the left eye, subsequent horizontal diplopia progressive over 1 month, and left ophthalmic and maxillary distribution of trigeminal numbness. A left orbital apex soft-tissue mass diagnosed radiologically (Figure 1) was thought likely to be inflammatory. He was treated with high-dose steroids and 6 courses of intravenous cyclophosphamide, with no improvement. On completion of treatment (at 7 months from presentation) there was evidence of clinical and radiological progression (Figure 1) with increasing left ocular pain, proptosis, partial ptosis, ophthalmoplegia, left visual acuity reduced to counting fingers, an unreactive left pupil, left ophthalmic and maxillary trigeminal anesthesia to light touch and pinprick, and an absent left corneal reflex. Differential diagnoses of indolent infection or lymphoma were entertained and open biopsy was planned. Because of rapid deterioration, this procedure was brought forward urgently. The lesion was debulked by a left lateral orbitotomy. Histological diagnosis was keratinizing squamous cell carcinoma (SCC) infiltrating soft tissue (Figure 2). Adjuvant treatment with radiotherapy (66 Gy) was administered, aiming for local control of the disease.

There are 4 reports of primary orbital SCC in the liter- ature $^{1,2}$ (on searching PubMed for "squamous cell carcinoma" orbit). There is an established link between GPA and SCC of the skin, anus, and nasal cavity $3,4,5$, but no mention of a history of GPA or autoimmune disease in any of the orbital cases.

SCC should be included in the differential diagnosis of orbital apex tumors. Surgical biopsy may guide treatment at an earlier diagnostic stage.

\section{REFERENCES}

1. Saha K, Bonshek R, Leatherbarrow B. Primary orbital squamous cell carcinoma. Clin Exp Ophthalmol 2011;39:582-4.

2. Peckinpaugh JL, Winn BJ, Barrett RV, Jacobsen DW, Sires BS, Meyer DR, et al. Isolated squamous cell carcinoma of the orbital apex. Ophthal Plast Reconstr Surg 2012;28:e72-4.

3. Knight A, Askling J, Ekbom A. Cancer incidence in a population-based cohort of patients with Wegener's granulomatosis. Int J Cancer 2002;100:82-5.

4. Wakisaka N, Tanaka S, Nagayama I, Furukawa M. Squamous cell carcinoma of the nasal septum with Wegener's granulomatosis treated with cyclophosphamide and corticosteroids. Auris Nasus Larynx 1998;25:393-6.

5. Stein J, Sridharan ST, Eliachar I, Niv A, Wood B, Hoffman GS. Nasal cavity squamous cell carcinoma in Wegener's granulomatosis. Arch Otolaryngol Head Neck Surg 2001; 127:709-13.

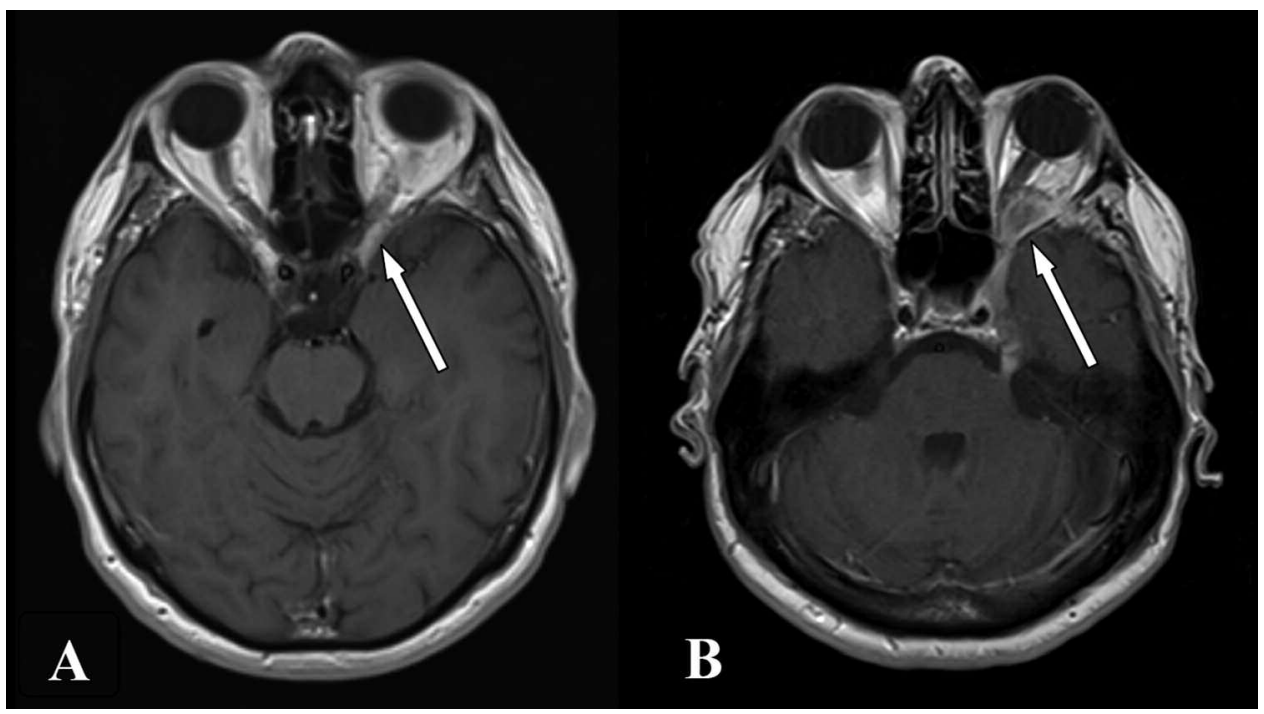

Figure 1. T1-weighted gadolinium-enhanced axial magnetic resonance imaging scans show progression of the orbital apex lesion (white arrow) from diagnosis (A) to requiring biopsy/debulking (B). 

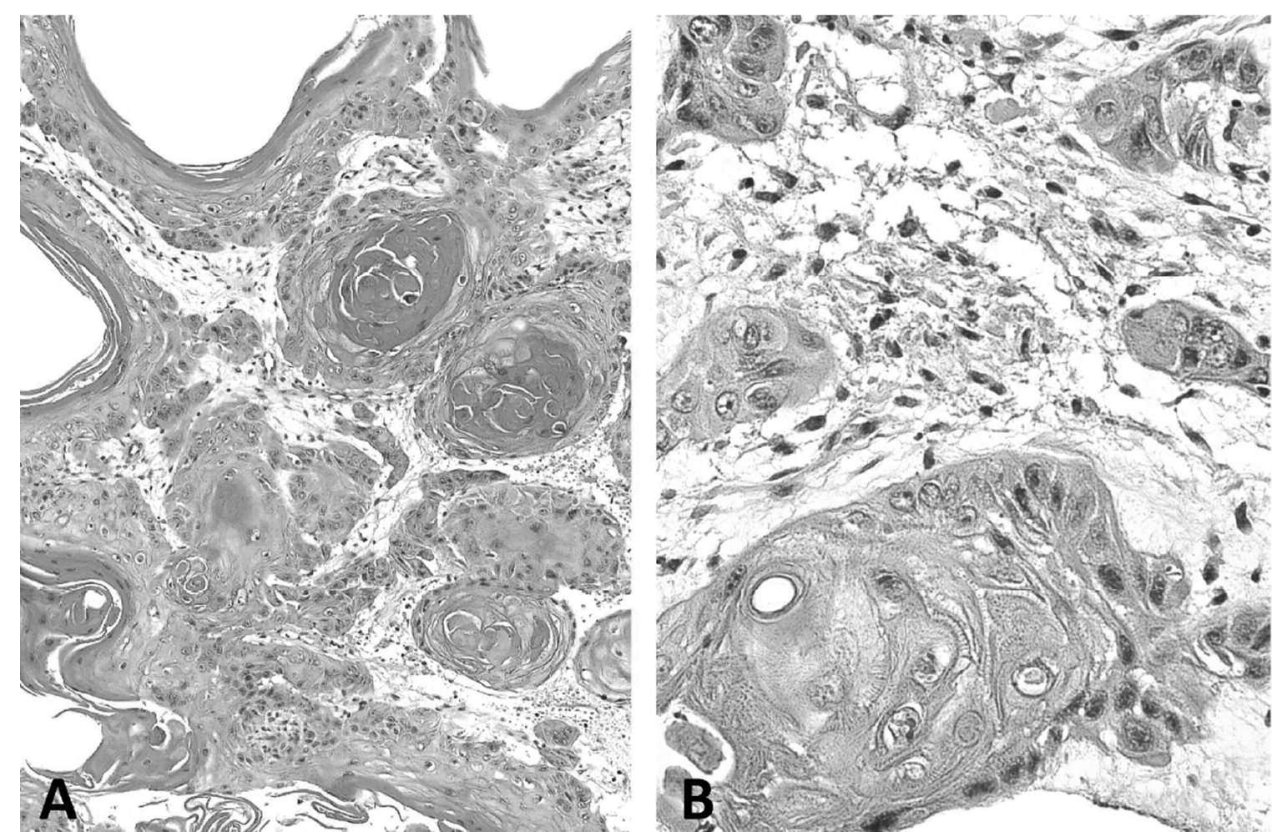

Figure 2. Morphological features of the tumor. A. Sheets and nests of atypical stratified squamous epithelium with widespread surface keratinization and infiltrative growth pattern. H\&E stain; scale bar $=100 \mu \mathrm{m}$. B. Intercellular bridges are prominent. H\&E stain; scale bar $=20 \mu \mathrm{m}$. 